\title{
DYSTONIA, AUTOIMMUNE DISEASE AND CEREBRAL WHITE MATTER ABNORMALITIES IN A PATIENT WITH 18P DELETION
}

\author{
Carla Graziadio', Rafael Fabiano Machado Rosa, ${ }^{1,2}$, Paulo Ricardo Gazzola Zen ${ }^{1,2}$, \\ Louise Lapagesse de Camargo Pinto', Liselotte Menke Barea ${ }^{3}$, Giorgio Adriano Paskulin ${ }^{1,2}$
}

Dystonia is a clinically and genetically heterogeneous disorder of movement characterized by involuntary and sustained muscle contractions and rigid postures affecting one or more sites of the body. It can be classified according to the distribution of affected body parts, age of onset and etiology'. Up to now, at least 15 different loci (DYTT-DYT75) have been described in this condition ${ }^{1,2}$. Adult-onset idiopathic torsion dystonia affecting specific parts of the body, such as the eye (blepharospasm), neck (cervical dystonia), and hand (writer's cramp) has been associated with the DYT7 locus, located in the short arm of chromosome $18^{1-3}$. Autoimmune diseases have been considered conditions associated with reactions of the immune system against selfantigens or body systems. They are disorders often associated with severe and chronic morbidity. In spite of recent advances, much of their etiology is still unknown ${ }^{4}$.

We describe a rare case of a patient with $18 p$ deletion syndrome presenting focal dystonia, Hashimoto thyroiditis, vitiligo and cerebral white matter abnormalities.

\section{CASE}

The patient is a 30 year old white woman, the fourth child of a non-consanguineous couple, without any history of similar cases in the family. The patient was born full-term, with a Cesarean section, after a pregnancy without intercurrences. During her first year of life, she had several episodes of infection (otitis and tonsillitis) as well as constipation where laxative use was needed. At 3 months, she had a convulsive crisis during fever. In relation to her neuropsychomotor development, the mother recalls she supported her own head at 6 months and pronounced her first words at the age of three. The patient was also unable to accompany normal school, failing several grades. After a long period without intercurrences, she began with blepharospasm together with cervical dystonia. She presented telarche at the age of 12 and menarche at 13 , and at around 20 she began with menstrual irregularity. The hormonal evaluation conducted later diagnosed hypothyroidism due to Hashimoto thyroiditis.

During the physical exam at the age of 30 , she presented obesity (weighing $70 \mathrm{~kg}$, between the 90-97 percentiles), short stature ( $149 \mathrm{~cm}$, under the 3 percentile), brachycephaly, but without microcephalia (head circumference of $53 \mathrm{~cm}$ - between the 2-50 percentiles), rounded face, ocular hypertelorism (interpupillary distance higher than the 97 percentile), ptosis, blepharospasm, corneal opacification, hypoplasia of the middle third of the face, broad nasal bridge, high palate, short and broad neck, low posterior hairline, broad thorax and accentuated cervical kyphosis (Figs 1A and B). She also had dextroconvex thoracic scoliosis, small hands and feet with hyperconvex nails (Figs $1 \mathrm{C}$ and D) and achromic spots of different sizes, spread about the body (thorax, dorsum and members), and vitiligo was diagnosed. The face remained in a fixed position, always turned to the right and downwards (Figs 1A and B). Nuclear magnetic resonance of the skull revealed a dilated ventricular system, with the presence of multiple hypersinal foci at T2 and DP in the semi-oval centers, without gadolinium impregnation, suggestive of demyeliminating lesions, and around the lateral ventricles and third ventricle, suggestive of periependimal leukomalacia (Fig 2A). Electroencephalograph assessment was normal. The thorax radiograph revealed hyperkyphosis with a reduction in body height at the seventh thoracic vertebra and dextroconvex thoracic scoliosis. Ophthalmological evaluation verified the presence of intense photophobia, bilateral keratocone with lower conjunctival pannus in the right eye and the entire left eye. Chromosomal analysis through GTG banding karyotype revealed a deletion involving the short arm of chromosome 18: 46,XX,del(18)(p11.1) (Figs 2B and $2 \mathrm{C}$ ). The karyotype of the parents was normal.

\section{DISTONIA, DOENÇA AUTOIMUNE E ANORMALIDADES DA SUBSTÂNCIA BRANCA CEREBRAL EM PACIENTE COM DELEÇÃO 18p}

Universidade Federal de Ciências da Saúde de Porto Alegre (UFCSPA) and Complexo Hospitalar Santa Casa de Porto Alegre (CHSCPA), Porto Alegre RS, Brazil: 'Clinical Genetics, Universidade Federal de Ciências da Saúde de Porto Alegre (UFCSPA) and Complexo Hospitalar Santa Casa de Porto Alegre (CHSCPA), Porto Alegre RS, Brazil; ${ }^{2}$ Graduate Program in Pathology, UFCSPA; ${ }^{3}$ Neurology, UFCSPA and CHSCPA.

Received 13 January 2009, received in final form 4 May 2009. Accepted 11 May 2009.

Dr. Giorgio Adriano Paskulin - Clinical Genetics UFCSPA - Rua Sarmento Leite 245 / 403 - 90050-170 Porto Alegre RS - Brasil. E-mail: paskulin@ufcspa.edu.br 


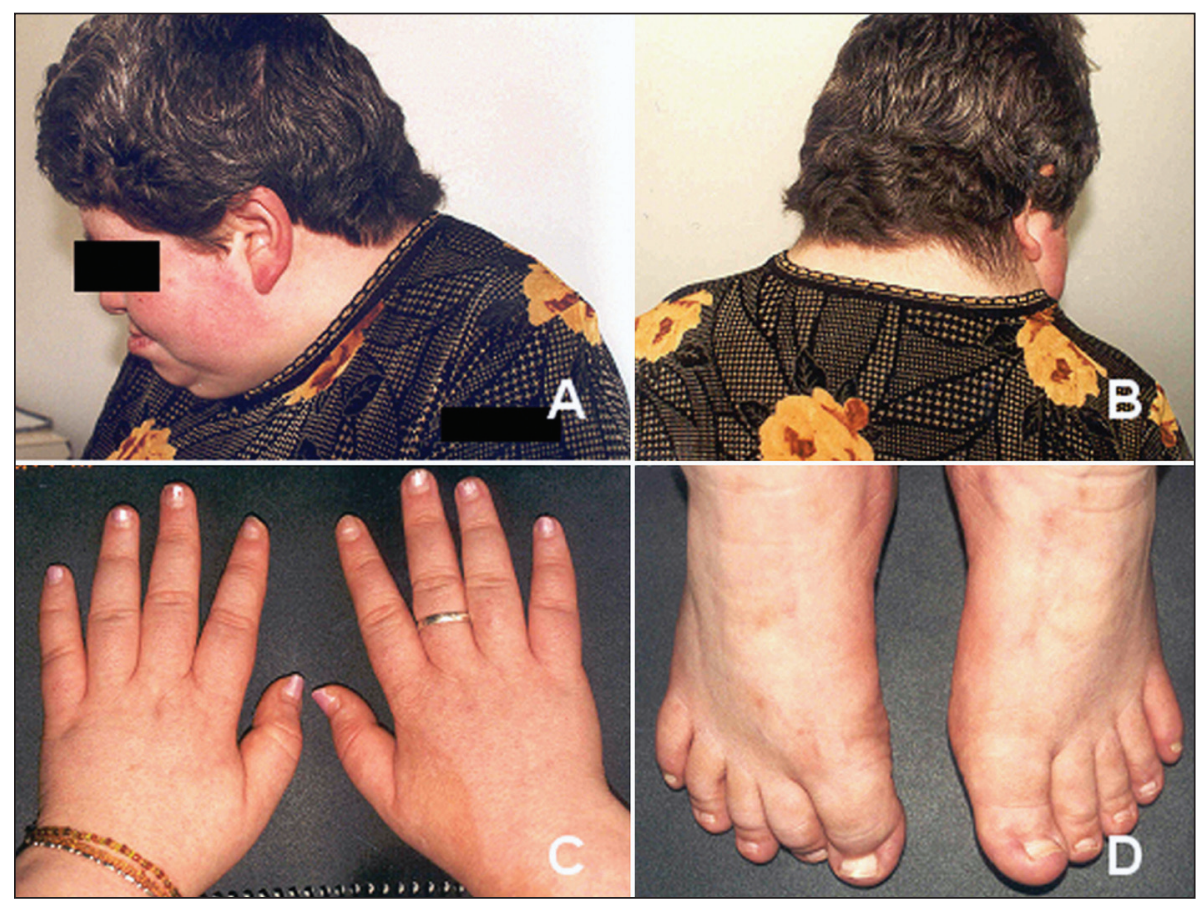

Fig 1. Craniofacial aspect of the patient showing the short and wide neck [A and B], as well as the low posterior hairline $[B]$. Observe the face position that is turned to the right and down [A and B]. Photos of the hands $[C]$ and feet $[D]$ of the patient, presenting small sizes and hyperconvex nails [C and $D]$.
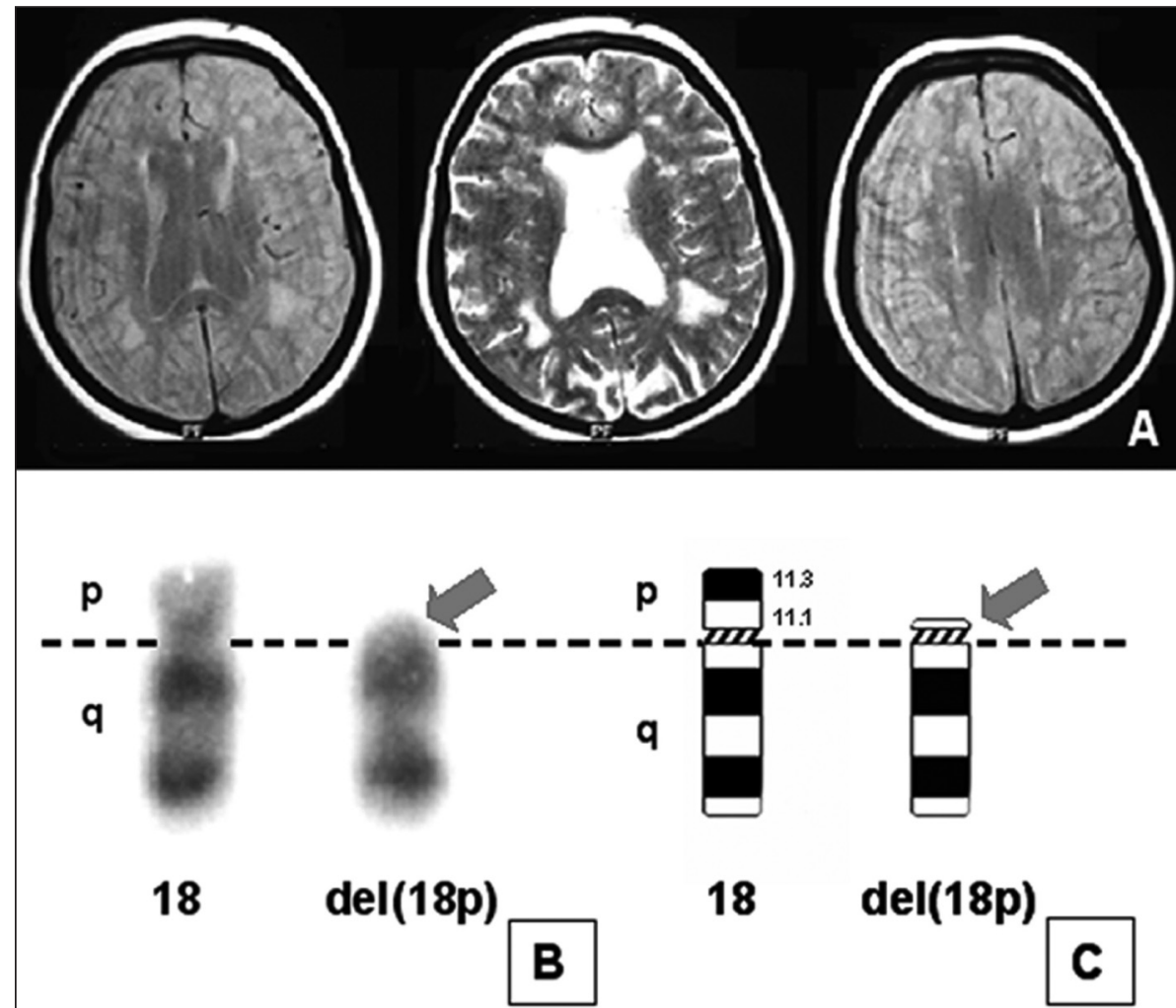

Fig 2. Magnetic resonance image of the skull revealing a dilated ventricular system, with the presence of multiple hypersinal foci around the lateral ventricles and third ventricle, suggestive of periependimal leukomalacia, and at T2 and DP in the semi-oval centers, without gadolinium impregnation, suggestive of demyeliminating lesions [A]. Partial GTG banding karyotype [B] and ideogram [C] showing a normal chromosome 18 (18) and the one with deletion involving the short arm of chromosome 18 [del(18p)]. The arrows indicate where deletion occurred. 


\section{DISCUSSION}

In 1963, De Grouchy was the first to report a distinctive condition associated with chromosome 18p deletion. Nowadays, it is known that it consists of a contiguous gene deletion syndrome. Although most reported cases have been sporadic, familial cases have been reported. The clinical phenotype of the 18p deletion syndrome varies widely among individuals, but usually comprises mental deficiency, hypotonia, craniofacial dysmorphia with ptosis, rounded face, micrognathia, large protruding ears and short neck, besides foot and hand abnormalities. Short stature is considered the most frequent feature. On the other hand, dystonia is a rare finding among these patients ${ }^{5}$. Up to now, only six cases have been reported, three associated with abnormalities of the white matter as in our patient ${ }^{2,6-8}$. Cerebral abnormalities usually described in these individuals include agenesis of corpus callosum, holoprosencephaly and arhinocephaly ${ }^{5}$. The dystonia is probably related to involvement of the DYT7 loci, located in the short arm of chromosome 18 and already associated with a form of autosomal dominant focal dystonia, a frequent cause of idiopathic torsion dystonia in central Europe?.

Autoimmune diseases have also been rarely described in patients with $18 p$ deletion syndrome. Hashimoto thyroiditis, for example, was reported only once ${ }^{9}$ and the present report represents the first description of a patient presenting vitiligo. However, it is interesting to note that other immune-mediated disorder, alopecia areata, has been linked to a loci of susceptibility in chromosome $18 p$ and this disease frequently coexists with autoimmune vitiligo and thyroiditis ${ }^{10}$.
Thus, patients with 18p deletion syndrome should always be carefully evaluated for symptoms of dystonia and autoimmune diseases, as vitiligo and thyroidtis. Maybe the low rate of cases presenting these features could be related to the fact that most patients described in the literature are children, and these symptoms usually start to occur later, especially in the second decade of life. Furthermore, as well pointed out by other authors ${ }^{6}$, chromosomal analysis should also be considered in cases of dystonia, mainly associated with other findings, like mental deficiency, short stature and dysmorphic features.

\section{REFERENCES}

1. Németh $\mathrm{AH}$. The genetics of primary dystonias and related disorders. Brain 2002;125:695-721.

2. Nasir J, Frima N, Pickard B, Malloy MP, Zhan L, Grünewald R. Unbalanced whole arm translocation resulting in loss of $18 \mathrm{p}$ in dystonia. Mov Disord 2006;21:859-863.

3. Dauer WT, Burke RE, Greene P, Fahn S. Current concepts on the clinical features, aetiology and management of idiopathic cervical dystonia. Brain 1998;121:547-560.

4. Williams Jr, RC. Autoimmune disease etiology: a perplexing paradox or a turning leaf? Autoimmune Rev 2007;6:204-208.

5. Turleau C. Monosomy 18p. Orphanet J Rare Dis 2008;3:4.

6. Tezzon F, Zanoni T, Passarin MG, Ferrari G. Dystonia in a patient with deletion of 18p. Ital J Neurol Sci 1998;19:90-93.

7. Klein C, Page CE, LeWitt P, et al. Genetic analysis of three patients with an 18p- syndrome and dystonia. Neurology 1999;52:649-651.

8. Awaad Y, Munoz S, Nigro M. Progressive dystonia in a child with chromosome 18p deletion, treated with intrathecal baclofen. J Child Neurol 1999;14:75-77.

9. Gluckman PD. Autoimmune thyroiditis in a case of $18 \mathrm{p}$ - syndrome. Aust Paediatr J 1977;13:122-124.

10. Martinez-Mir A, Zlotogorski A, Gordon D, et al. Genomewide scan for linkage reveals evidence of several susceptibility loci for alopecia areata. Am J Hum Genet 2007;80:316-328. 